\title{
The learning management system (LMS) discussion board as change agent
}

\section{Eva Dobozy}

\author{
School of Education \\ Curtin University \\ E-mail: eva.dobozy@curtin.edu.au
}

\begin{abstract}
Taking the concept of 'Learning Design' as a starting point, this paper explores design decision for the construction of a joint Blackboard site with embedded discussion board for students studying the same unit in either on-campus or online mode. In particular, the discussion board was designed to function as a communal space and central meeting point, inviting the disparate groups to 'mingle' and engage in border crossing behaviours and informal ethics training. The discussion board design was approached from a 'built pedagogy' perspective in conjunction with Learning Design principles and was underpinned by a Bourdieuian dispositional theory of action standpoint. This paper will provide an argument for the need to break down artificial barriers between learners and will illustrate how discussion boards can be employed to function as change agents.
\end{abstract}

Keywords: Learning Design, built pedagogy, Bourdieu, discussion board, change agent, passive students, lurkers, communicative action, communal learning space, connectivism, $21^{\text {st }}$ century learning, knowledge workers.

Reference to this work should be made as follows: Dobozy, E. (2013) 'The learning management system (LMS) discussion board as change agent', International Journal of Continuing Engineering Education and Life long Learning, special issue on: "Ethical and/or moral issues around the use of online discussion boards, with focus on the aspect of community building by way of computermediated communication", Vol. xxx, No. xx, pp. xxxx.

Bibliographical notes: Eva Dobozy is a Senior Lecturer in the School of Education at Curtin University. Her research interests can be located in the twin areas of Learning Design (LD) and Learning Analytics (LA) and centre on the exploration and documentation of intent and impact of pedagogical decision-making.

\section{$1 \quad$ Introduction}

The current revolution in universities is putting teaching under the spotlight, which at least provides an opportunity for some reflection on current practice.

John Biggs, 2012, p. 54

This paper explores design decisions for the construction of a joint Blackboard site for students studying the same unit in either on-campus or off-campus mode. Blackboard is the university's current learning management system and extensively used in all disciplines in a variety of ways. The question of the need for a joint unit Blackboard site for different student groups and the particular focus on design decisions is an interesting one and will be explored in this paper. However, a short and obvious answer is provided up front: Learning spaces, physical and/or virtual, have a profound impact on learners and learning and hence need to be carefully designed. It is the first time the author has experimented with the design of a joint 
Blackboard site for different student groups and this paper provides an illustration of the design journey of aligning on-campus and off-campus learning experiences with the aim of shifting students' learning habits from information consumption to knowledge production.

As we approach the midpoint of the second decade of the 21 st century we gain a better understanding of the need of future knowledge workers' skills and capacities. There is increasing evidence that the future workforce will need to be equipped to increasingly tackle as yet unimaginable challenges, which demand novel and innovative mindsets and employees ready to work in collaboration with others to explore strategies that are new and untested. Understanding the challenge of developing $21^{\text {st }}$ century knowledge and skills and how best to foster ethical decision-making and action in students, traditional teacher-centric and contentdriven pedagogies are increasingly displaced by learning-centric approaches, as student learning experiences in higher and further education are becoming more active and experiential. Following in the footsteps of well-known constructivist learning theorists, such as Carl Rogers (1969), John Dewey (1944/1994) and many others, and more recent connectivist learning theorists, such as Terry Anderson (2013), Stephen Downes (2013), and George Siemens (2006), learning-centric education is defined as follows:

Learning-centric education is the effortful exploration and articulation of Learning Design decisions and their impact on student learning engagement and learning outcomes, based on the assumption that learners are involved in self-authoring practices and are capable and willing to take meaningful control over their learning. (Dobozy, in press)

The aim of learning-centric education is the re-establishment of holistic educational principles and practices that balance the cognitive/intellectual achievements with the noncognitive, psychosocial competencies of learners. Shechtman et al. (2013) explain this idea pointedly when they note:

The test score accountability movement and conventional educational approaches tend to focus on intellectual aspects of success, such as content knowledge. However, this is not sufficient. If students are to achieve their full potential, they must have opportunities to engage and develop a much richer set of skills. There is a growing movement to explore the potential of the "noncognitive" factors-attributes, dispositions, social skills, attitudes, and intrapersonal resources, independent of intellectual ability - that high-achieving individuals draw upon to accomplish success. (Shechtman et al., 2013, p. 1)

The desire for more learning-centric educational experiences coupled with the increased use of digital technologies has greatly impacted learning and teaching patters (Anderson and Dron, 2012; Shechtman et al., 2013). Enabling greater student-to-student engagement with learning content based on Learning Design principles, means opening an avenue for shifting student mindsets from passive consumer students to active producer students. Students need to be active knowledge producers, because "knowledge is defined by its creation through activities" (Anderson and Dron, 2012, slide 30). Consumer students are, so the author has argued previously (Dobozy, 2011, Dobozy 2012a), students who are used to and comfortable with being passive recipients of pre-packaged and highly accessible and easily digestible information, which is misaligned with the demands placed on $21^{\text {st }}$ century knowledge workers (Su, 2012). The need for producer students, who develop a wide verity of technical and generic cognitive and non-cognitive skills in combination with ethical conciseness, has been reaffirmed by a recent survey of employers. When asked: "What skills are you looking 
for when you hire" respondents on the Millennial Branding (2012) survey identified the following top three competencies:

- Communication (98\%)

- Positive attitude (97\%)

- Adaptable to change (92\%)

This expectation of future employees as active, collaborative, open-minded, tolerant and flexible workplace participants is mirrored in the demands placed on students in purposely built networked learning environments. The effortful engagement demanded in collaborative, discussion-based learning environments takes considerable time and often the learning outcomes are not as easily seen as testable technical knowledge. Producer students will need to learn to think on their feet, be prepared to be challenged on their taken-for-granted views and work through ill-structured real-world problems (Shechtman et al., 2013). In an earlier publication, the author refers to these learning activities as 'mess management' (Dobozy, 2011). These producer students need not only be able, but foremost willing, to embrace ambiguity, change, and partiality of information. They will need to step outside of their comfort zone and embrace the idea of 'giving and participating', for this they need to be socially and cognitively present. Hence, they will need to be willing to learn collaboratively and test their current ideas and values through the engagement in a networked learning community. Creating such learning spaces is not an easy undertaking and fraught with many design challenges. To illustrate the design journey, the dialectic relationship between the learner and the learning environment is explored next from a Bourdieuian dispositional theory of action perspective and connected to learner agency and decision-making power. Then, the concept of Learning Design is briefly introduced and connected to the notion of 'built pedagogy'. These theoretical underpinnings have been taken as a starting point for the design of a joint unit Blackboard site with interconnected discussion board for students enrolled in a new Bachelor of Education course and studying either in an on-campus or fully online mode. Finally, some challenges are outlined that demonstrate the difficulties of shifting student mindsets to facilitate the ideas of border crossing and agency as informal ethics training.

\section{Bourdieuian dispositional theory of action perspective}

Pierre Bourdieu's $(1977,1990)$ work is seen most useful in understanding the need to create learning spaces that represent diversity and provide ample opportunity to 'mingle and connect'. Bourdieu's work on cultural capital and habitual action (habitus) is well known. Bourdieu acknowledges the difficulty of cultural change practices, such as enticing students to move into 'producer model' and leave the comfort of passive information consumption behind. He notes that there is a dialectical relationship between the learner and the learning environment. The learner is socialised into particular ways of being 'a student', which means that the cultural experiences as forms and habits of cultural behaviours and role expectations of learners and teachers are formed and cemented into taken-for-granted expectations. The dialectic relationship as outlined by Bourdieu (1977) refers to this mutual influence between the individual, the situation and past experiences and the presence or absence of certain characteristics of the learning environment. Bourdieu explains:

The product of a dialectical relationship between a situation and the habitus, understood as a system of durable and transposable dispositions which, integrating all past experiences, functions at every moment as a matrix of perceptions, appreciations, and actions. (1977, p. 261) 
Hence, habitus is highly significant in reaffirming and reproducing or challenging traditional cultural practices. Learner expectations of (non)actions and behaviours, underpinned by past experiences are deeply influential in shaping role expectations and dispositions. Bourdieu argues that culture is the interplay between structural components and the individual and is actively constructed through the interrelationship of role expectation and habitual action, which may limit students' possibilities of agency and meaningful, ethical participation in communal activities. Guzzini explains that:

Bourdieu's starting point is not the agent, but always the structure, the structure itself is defined as a set of practices, rather than substance, and a set of relations of positions, which are in potential flux, a set of socially defined (but not determined) roles and subjects, as it were." (2006, p. 21)

In a traditional learning space, for example, the classes are divided and strictly organised and the expectation is for a teacher, as the expert, to 'teach' in the sense that students will wait to be told what, when, how and how much to do. Hence developing a 'different mindset' concerning the value of informal and incidental peer-supported learning, such as semistructured discussion board activities, requires an understanding of power and agency as structural components rather than residing solely within the individual (Guzzini, 2006).

In effect, the shifting of culture in education and the development of a different mindset requires, according to Bourdieu, first and foremost an understanding of the value of moving traditional pedagogical practices from the formal to the informal and incidental realm. In other words, shifting cultural practices and with it the building of new learning and teaching spaces that makes possible the shifting of entrenched cultural practices requires the development of new cognitive structures and role expectations of both students and teachers (Fullan, 2008).

To assist students to move cognitively and emotionally from the pre-formed expectation and value of traditional formal learning, which entails a consideration of the value-adding nature of informal and incidental learning engagement, the virtual learning space design needed to adhere to learning principles that are aligned with the idea of equipping $21^{\text {st }}$ century knowledge workers with a mix of technical and generic knowledge and skills and attitudes of caring, tolerance and participation. The new field of Learning Design has emerged as a specialised field of education to grapple with this very problem.

\section{$3 \quad$ Learning Design (LD) and built pedagogy}

The educational field of Learning Design (LD) emerged out of the need to study and describe the development, implementation and adaption of particular learning designs created in various contexts and for multiple purposes (Conole, 2013). LD as a specific field of education, although relatively new, seems to be attaining a certain maturity (Dobozy, 2013). As an evolving field of study, LD is not primarily concerned with the learning content, but rather "the pedagogical approaches taken that support the learning of the required content" (Dobozy, 2012b, p. 43). Diane Oblinger (2006) refers to learning designs that focus on particular learning spaces, such as, discussion boards, as 'built pedagogy'. She notes that built pedagogy is "the ability of space to define how we teach" (p. 9). The "architectural embodiment of educational philosophies (Monahan, cited in Oblinger, 2006, p. 9), refers to ability of space to make possible or hinder certain actions to take place. Hence the ability of space to impact learner engagement with the teaching and learning material and with each 
other for the benefit of shared knowledge creation, but more importantly the building of new cohesive communities, should not be underestimated.

The aim of the design decisions taken in the creation of the jointly inhabited virtual learning spaces of teacher education students studying in either on-campus or online mode, was to transform teaching and learning practices using Blackboard's discussion board as a change agents. In other words, using the interrelated concepts of LD and 'built pedagogy', the Blackboard discussion board has been purposely designed to assist in the development of, on the one hand, academically mature students, referred to by Schmidt (2010, p. 6) as "cognitively autonomous individuals", and on the other hand, ethically-minded students able and willing to "progress towards an unknown future in which they will confront and influence changing real-life and career situations" (Su, 2012, p. 169).

Although it would be interesting to capture student perceptions and experiences of the joint learning space, this paper only documents the design of the architectural components of the jointly occupied virtual learning space. Hence, it emphasises the notion that through the deliberate planning and construction of virtual communal spaces, similar to the planning and construction of physical spaces and objects, it is possible to prepare learning environments that provide opportunities for formal and informal gathering and knowledge exchange. However, it is not possible to make learners use the 'prepared environment' in the way it was envisioned and designed. Thus, this paper argues that there is a need to pay close attention to the way design decisions are made when constructing new and innovative (virtual) learning spaces prior to the investigation of how these designed spaces are perceived as conducive to learning and how they are utilised differently by learners and teaching staff not involved in the design. Although it is outside the scope of this paper to do so, it is acknowledge that there is great value in investigating learner and tutor perspectives in relation to agency and how 'effective use', 'non-use', 'mis-use' and/or 'ab-use' of learning spaces and provisions can lend future insight into how students learn differently and what design decisions need to be adopted and what adaption made to enhance the learning engagement of diverse learners and cater effectively for student variability.

\section{The interconnected discussion board design}

Community and networks stimulate and thrive on cognitive and psychosocial diversity. A culture of creativity and active participation can be deliberately designed to counterbalance spatial distance and enable constructive dialogue between individuals who are, for example, expected to work through the same learning content, but experiencing different delivery modes. Bringing voices from different places together allows people to share in a joint experience and co-create their understanding of the learning activates. So, the first design decision made was to visually illustrate 'sameness' and 'difference' by providing on the one hand, communal open spaces, and on the other hand, gated spaces, designated for particular student groups (e.g. on-campus or off-campus groups), but with open access for everyone (see Figure 1). 
Please start by listening to the iLecture recording (see below) or read through the Lecture Notes, which can be found here:

LLiDW_Lecture_2_Final_1.pptx

This should be followed by reading this week's text in preparation for the face-to-face tutorial or your online Learning Activities:

Main unit text: Chapters 1-3.

You are advised to take notes while listening to the lecture and also while reading your main unit text chapters.

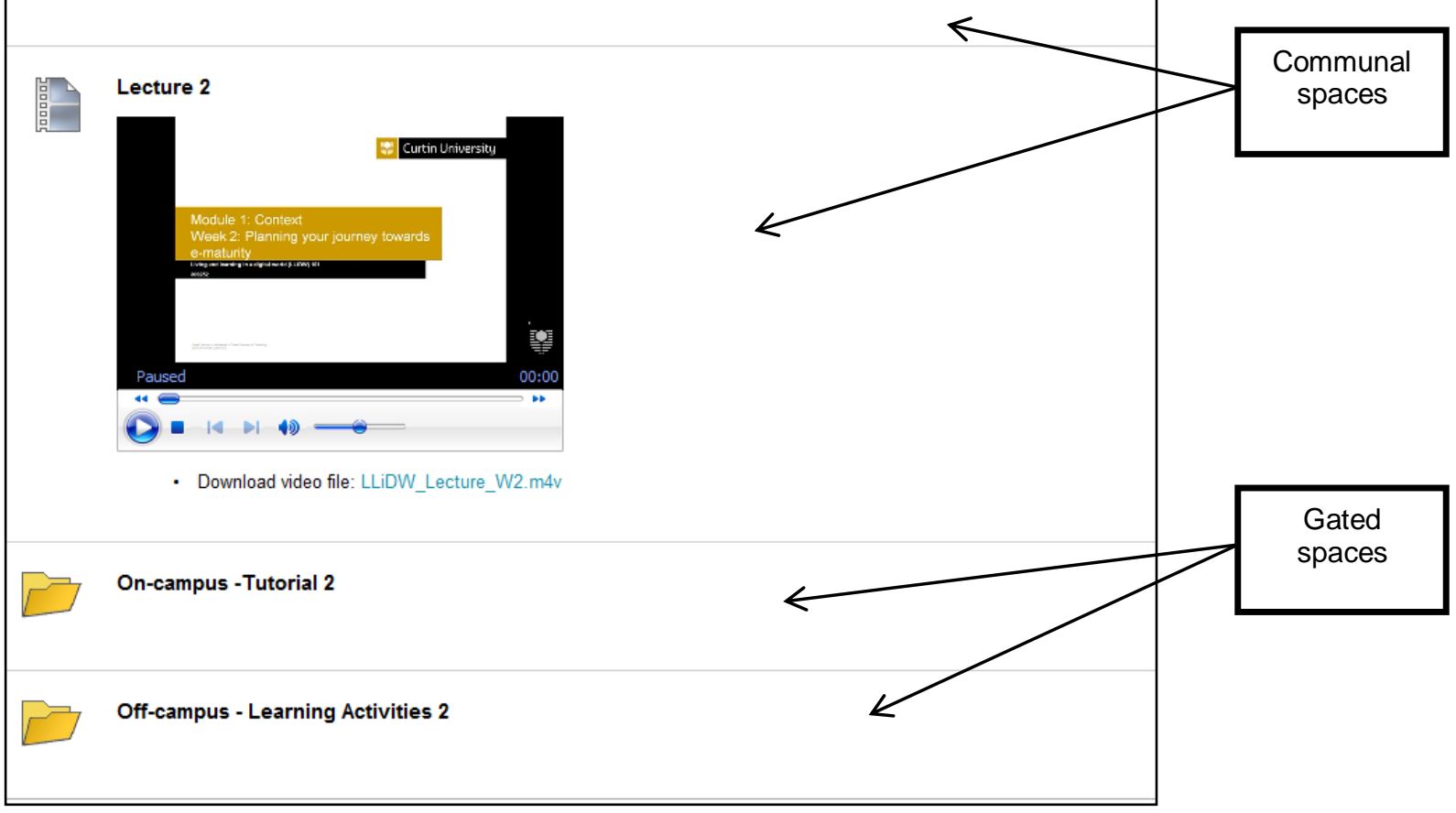

Figure 1 Open communal spaces versus gated spaces with 'open gates'

The design of both the communal spaces (joint introduction, multimedia resources, weekly audio lectures, and of course, the discussion board) and the gated spaces (specific folder depending on study mode with open access for everyone) was to provide spaces that enable mingling and spontaneous interaction, and therewith, the practising of active and caring participation in new communities. The built pedagogy or the design of a dynamic collaborative learning environment needed to be inviting, but also a little bit mysterious to build curiosity and social presence. A second deliberate design decision was made to entice students studying in both the on-campus and off-campus modes to become aware of the opportunities the new joint design offered to them as an 'amplified assistance' tool. For example, the learning activities for on-campus and off-campus studying students were closely aligned in the sense that the synchronous inter-group classroom discussion could be mirrored in an asynchronous discussion board based learning environment (see Figure 2). The advantage for students studying in on-campus mode was obvious. Whenever someone would miss one or multiple classes due to illness or other life events, they would be able to be directed straight to past and present learning activities posted in the folder for off-campus students (gated environment) and encouraged to engage in the activity-based online discussion. The increased flexibility that time and place shifting offered for students studying in on-campus mode ought to lead to fewer students disengaging from the learning activities or falling behind in their studies due to missing of class. 
Week 2 - Activity 1 (Portfolio - Matrix)

Week 2 - Activity 2 (Draft marking rubric)

Week 2 - Activity 3 (Reflection walk-through)

Week 3 - Activity 1 (low tech TEL - key word activity)

Week 3 - Activity 2 (Why TEL?)

Week 3 - Activity 3 (Your ePortfolio assignment)

Week 4 - Activity 1a (Spreadsheet)

Week 4 - Activity $1 \mathrm{~b}$ (MailMerge)

Week 4 - Activity 2 (Quiz questions)

Figure 2 Activity-based asynchronous online discussions, mirroring synchronous in-class interactions

To increase cross-sectional interaction and encourage border crossing behaviours in students, it was important to find a way to get students studying in on-campus mode to provide something of interest and value-adding to the learning experience of students studying in offcampus mode, using the discussion board as the main tool. Hence, a special learning activity was created, which was referred to as Topic Review and THM (take-home-message). Using the Topic Review - THM thread, students studying in on-campus mode were invited to not simply share their unique learning experience as a discussion item in class, but to post it as a discussion board entry (see Figure 3).

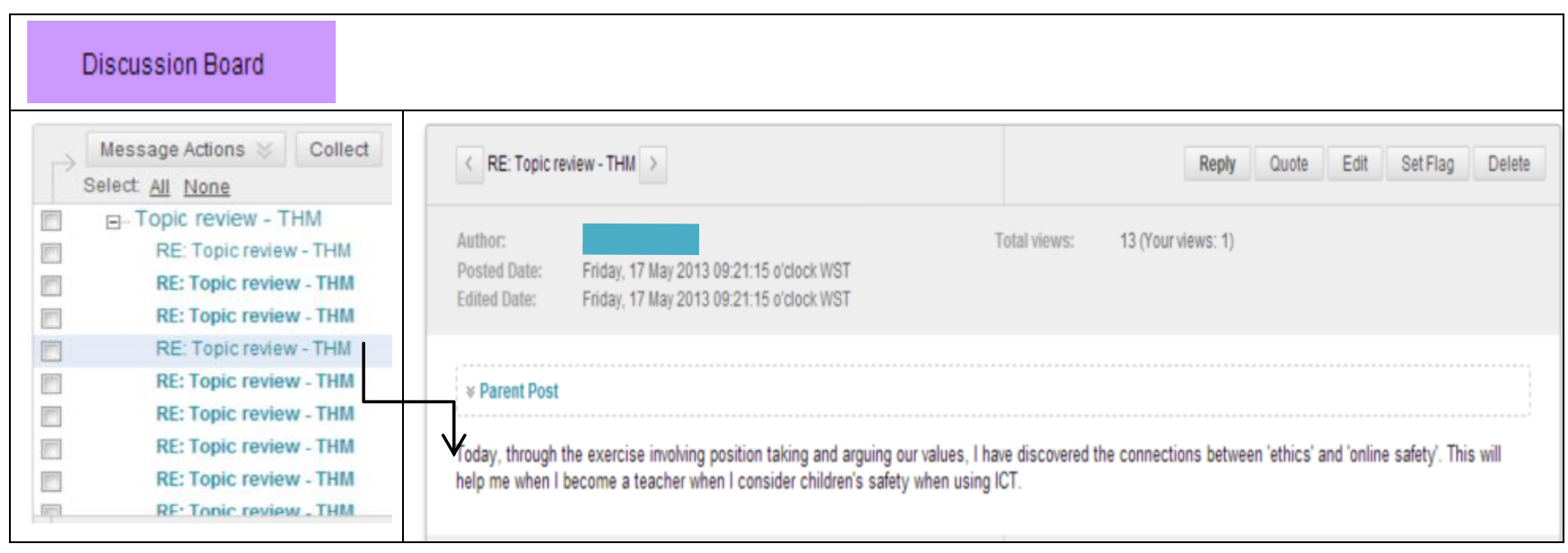

Figure 3 On-campus students' active contributions to the communal discussion board

Attending to students' lived experiences and inviting them to post personal accounts was intended to increase the traffic on the discussion board. More importantly, the Topic Review 
- THM served multiple purposes as students were discouraged from posting simple statements and unreflective personal opinions. Instead, they were invited to link their views and personal experiences with the unit learning outcomes.

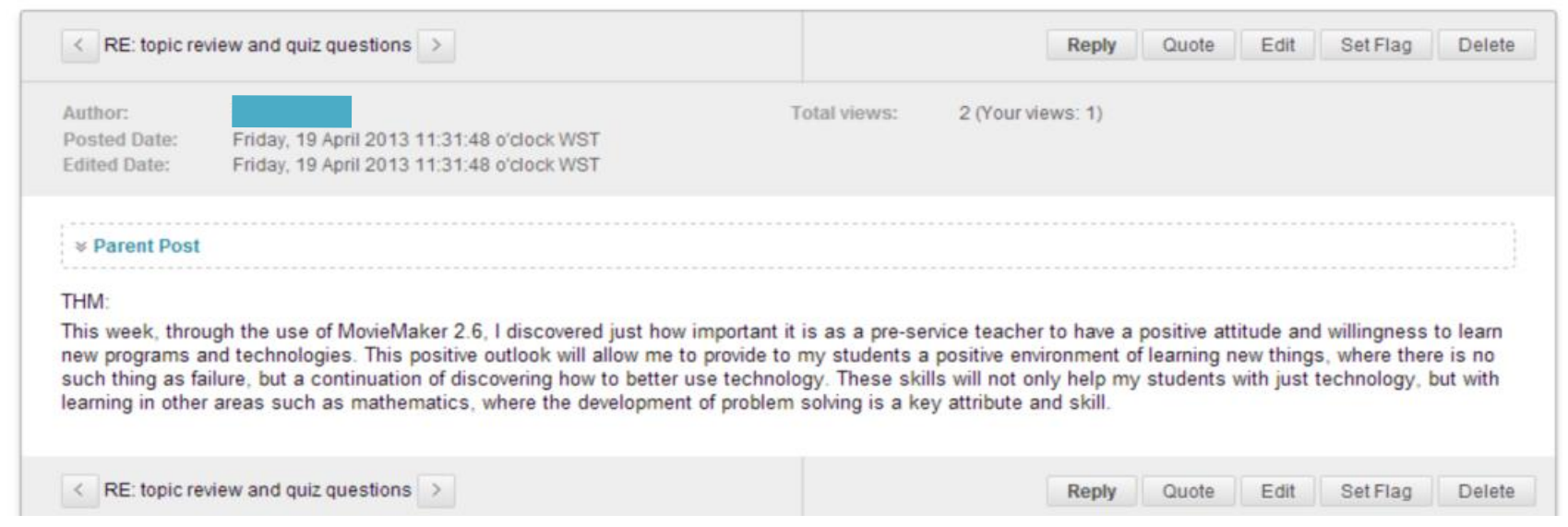

Figure 4 Topic review - THM (take-home-message) posted by on-campus students

Prior to posting their Topic Review - THM on the discussion board, the development of high quality reflective posts was practiced in class (see Figure 4). The effect was that students studying in face-to-face mode first verbally shared their weekly individual THM with their peer group and then also reproduced it on the communal discussion board space. These students demonstrated social and cognitive presence in communal spaces. More importantly, they practised higher order thinking, deep learning and were able to motivate others to follow suit and share their lived experiences and how different aspects of their learning engagement contributed to their learning. Not only were they engaged in technical knowledge exchange, but through the weekly posting and responding to ideas posted by others, these students engaged in informal ethics training through the demonstration of active knowledge sharing, the enactment of caring behaviours and the building of social cohesion among groups of students that do not normally meet and mingle. A key motivation for the current design was, however, the idea that this 'mingling' and active posting on communal sites, would contribute to students' growing development of a group culture or culture of participation and a growing understanding of the value-adding nature of peer networking and network formation. In other words, the various design aspects were aimed to provide informal learning experiences, and foster interdependency, free sharing of ideas and personal experiences.

As a means of attendance verification, the third design decision was taken to get all students to self-enrol in each activity-based discussion thread on the discussion board. A key reason for this design decision was the need to distinguish between students who would be altogether absent from the communal learning space and lurking students. Distinguishing between absent students and lurking students in virtual learning environments has been previously acknowledged as being hard, if not virtually impossible (Dennen, 2008). An absent student is someone who is disengaged and absent from the learning space. By contrast, a lurking student, or lurker, is someone, who is an "invisible participant" (Soroka and Rafaeli, 2006), not typically engaged in discussion, but still socially present. In other words, lurking students make an effort to visit communal spaces. Hence, the value of the digital social presence of lurkers within the communal learning space should be captured. A first step into changing passive learning behaviours is to entice students to commit to becoming visible and, hopefully, vocal. Inviting lurking students to commit to more active learning behaviours was 
in this case achieved through deliberate design and the construction of a particular architectural feature. Everyone attempting to 'mingle' in the communal space of the discussion board needed to become visible and actively sign up to the various discussion board thread (see Figure 5). Although learners who have been socialised into and are comfortable with particular ways of being a student, such as being 'invisible' and a passive consumer of information, the habits of passivity may be changed through particular design decisions and the construction of specific architectural features, such as a 'sign up' function. Hence, the need for action, even for lurkers, may mean that the relationship between past learning experiences, learning expectations and the absence or presence of student action or student passivity may be broken as lurking students will need to come out of the shadow.

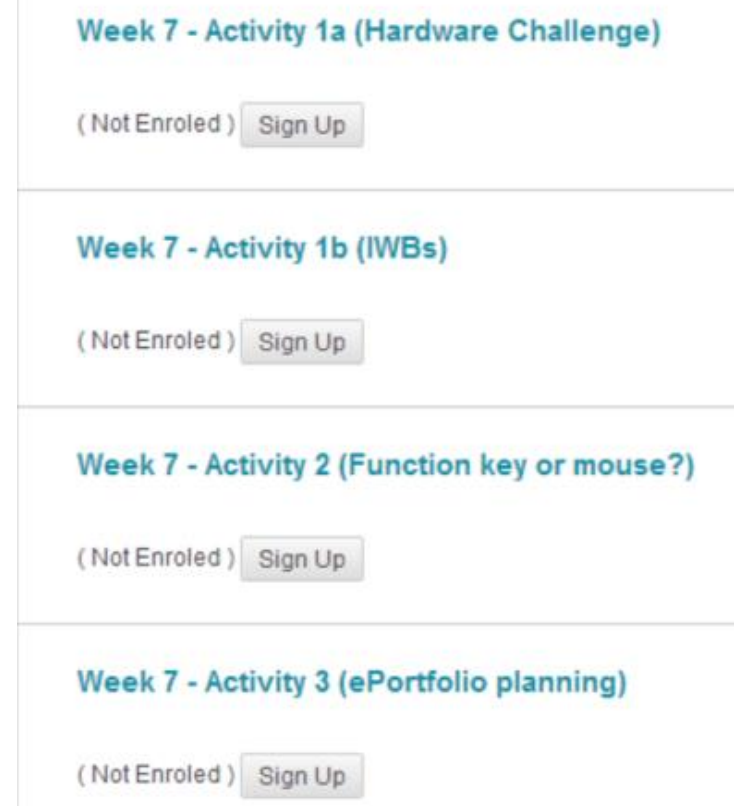

Figure 5 Designing for action: the discussion board as change agent

Another reason for this specific architectural design was to be able to verify the success rate of students' border-crossing behaviours and the students' willingness to engage in a discourse of border-crossing, moving in and out of communal and gated spaces and engaging with learning activities designed for the other group. In this way, learning can be reconstituted as an interplay between formal and informal engagement with the assigned learning material and more importantly with each other, leading to a shift in cultural practices.

\section{Discussion}

Students' ethical behaviours play an increasingly important role in their acquisition of new technical or generic knowledge and skills. Hence, the design of learning environments that enhance student interaction and the possibility of informal ethics training through active and meaningful communication is becoming increasingly important. However, a key barrier to educational change practices is the traditional didactic approach taken by many higher education lecturers. For example, Avaraamidon and Ecomomon (2011) note that: "in several cases, teachers seemed to be hesitant adopting a new design methodology ... that stems from their personal beliefs and teaching experiences" (p. 113). Similarly, Kordaki (2010) 
contended: "teachers need more support in the design of collaborative online learning designs, which effectively enhance engagement and deep learning" (p. 66). The three interconnected learning design decisions that illustrate sameness and difference and invite students to mingle in both communal and gated spaces to engage in informal ethics training and the building of community cohesion, was an example of built pedagogy, based on Learning Design principles that are underpinned by social constructivist and connectivist learning theories. The aim was to cater for the demands of a new world and prepare teacher education students who are able and willing to shift from a position of passive consumer students to a position of social presence, mingling in communal spaces and 'lurking', showing interest in what is happening, if they are not yet prepared to actively contribute to activity-based online discussions. This option was made possible through specific design decisions, creating open communal spaces, such as the introduction and resource page within the unit Blackboard site (Figure 1), but also the discussion board sites, which required active sign in to be accessed by students (see Figure 5). The value of social presence in communal online spaces should not be underestimated and may present a safe place for lurker students to start engaging more actively with the learning materials, but most importantly and with other students, instilling in them an idea that presence matters. The difference between absent students and lurker students in online discussion boards is that lurkers can be invited to engage in informal and incidental (ethics) training, whereas absent students are disengaged from the learning community. The possibilities of engaging lurker students will need to be acknowledged and demand better understanding.

The aim of the learning management system (LMS) discussion board architecture was for it to function as a change agent in the building of new communities. Students needed to demonstrate some behavioural change and action to access the communal spaces and engage in the building of new communities, showing caring behaviours and particular actions that contributed to social cohesion. To indicate 'social presence' within the discussion board communal spaces, lurker students needed to self-enrol, making visible their presence to everyone who was occupying this space. Moreover, this design decision enabled, through the attendance verification process, the distinction to be made between socially present and absent students, which is vital for informal ethics training.

\section{Conclusion}

There is increasing recognition that learning spaces, such as deliberately designed unit Blackboard sites and discussion boards, have a profound impact on learners and learning. Design decisions can support or hinder certain forms of learning, such as formal, informal or incidental. Motivating students to be present in online learning spaces and show interest in community-building activities is the first step to changing their habitual actions of being passive consumers of bit-sized information provided by teaches. However, active learning skills need to be developed and enacted. The paper explored specific design in the construction of the joint occupation of the virtual learning space by learners studying the same unit in either an on-campus or off-campus mode. The design decisions were underpinned by Learning Design principles and exemplified 'built pedagogy' architecture based on a Bourdieuian dispositional theory of action perspective. The three interlocking design decisions were to: (i) provide gated and communal spaces, (ii) build awareness of this design as 'amplified assistance', and (iii) demand self-enrolment to discussion board activities. The purpose of the documentation of this experimental design of a joint virtual learning space was to illustrate that the discussion board in the joint Blackboard unit site, can become change agents, supporting students' ethical online learning behaviour, their learning engagement and learning outcomes. 
The way in which the joint Blackboard site and discussion board in the present example has been created is to provide ownership of learning to students, but also to provide possibilities for students to move from a state of passivity to one where they have to 'enact' social presence by actively signing up to the activity-based communal discussion board threads. This act of signing up provided the educator with a way to monitor student action (lurking in communal spaces) or inaction (being absent altogether), but more importantly it may entice lurker students to commence contributing their ideas and knowledge and more actively subscribe to the building of the common good, fulfilling the promise of informal ethics training.

There is now clear and persistent evidence that learning-centric design based on constructivist and/or connectivist learning theories have a number of benefits that supports the development of cognitive and non-cognitive capacities in students, such as improved academic performance, increased intrinsic motivation and increased social conscience (Brew, 2010; Healey and Jenkins, 2009). The next step is to investigate the impact of this design on actual student ethical behaviours.

\section{References}

Anderson, T. (2013) Virtual Canuck: Teaching and Learning in a Net-Centric World, available at http://terrya.edublogs.org/ (Accessed 23 September 2013)

Anderson, T. (2010) Three generations of distance education pedagogy: Challenges and Opportunities, available at http://www.slideshare.net/terrya/three-generations-of-distanceeducation-pedagog $\mathrm{y}=$ challenges-and-opportunities (Accessed 9 June 2013)

Anderson, T. and Dron, J. (2012) 'It's hardly easy to be softly hard: Freedom and control in learning spaces'. Keynote address at the $8^{\text {th }}$ International Conference on Networked Learning. 2-4 April. Maastrich, the Netherlands.

Avraamidou, A. and Economou, A. (2011) 'Visualized Learning Design: The challenges of transferring an innovation in the Cyprus educational system'. Proceedings of the 6th International LAMS and Learning Design Conference. Sydney, NSW, Australia. pp. 108-116.

Biggs, J. (2012) 'What the student does: teaching for enhanced learning'. Higher Education Research and Development, Vol. 1, No. 1, pp. 39-55.

Bourdieu, P. (1977) Outline of a theory of practice. Cambridge University Press, Cambridge, England.

Bourdieu, P. (1990) The logic of practice. Polity Press, Cambridge, England.

Brew, A. (2010) Enhancing undergraduate engagement through research and inquiry. National Teaching Fellowship Report. Australian Learning and Teaching Council, Strawberry Hills, NSW, Australia.

Conole, G. (2013) Designing for learning in an Open World. Springer, New York, N.Y., United States of America.

Dennen V. (2008). 'Pedagogical lurking: Student engagement in non-posting discussion'. 
Computers in Human Behavior, Vol. 24 No. 4, pp. 1624-1633.

Dewey, J. (1944/1994). Democracy and Education. Institute for Learning Technologies (ILT) HTML markup - digital classics, available at http://www.ilt.columbia.edu/publications/dewey.html (Accessed 18 March 2013)

Dobozy, E. (in press) 'Situating case-based learning among other learning-centricpedagogies'. In: Claus Nygaard, John Branch, and Paul Bartholomew (Eds.). Improving university students' learning outcomes through case-based teaching. (pp. xxx), Libri Publishing, Faringdon, England.

Dobozy, E. (2013) 'Learning design research: advancing pedagogies in the digital age'.

Educational Media International, Vol. 50 No. 1, pp. 63-76

Dobozy, E. (2012a) 'The de Bono LAMS sequence series: Template designs as knowledgemobilising strategy for 21 st century higher education.' Teaching English with Technology Special Issue on LAMS and Learning Design, Vol. 12, No. 2), pp. 88-102

Dobozy. E. (2012b) 'Typologies of Learning Design and the introduction of a 'LD-Type 2' case example'. In: P. Ullmo and T. Koskinen (Eds), eLearning Papers - Special Edition 2012: Opening Learning Horizons. Barcelona, Spain.

Dobozy, E. (2001) 'Resisting student consumers and assisting student producers'. In: Claus Nygaard, Clive Holtham and Nigel Courtney (Eds.). Beyond Transmission: Innovations in University Teaching, (pp.11-16). Libri Publishing, Faringdon, England.

Downes, S. (2013) MOOC - The resurgence of learning community in online learning. Half an Hour [online] 30 May. http://halfanhour.blogspot.ca/2013/05/mooc-resurgence-ofcommunity-in-online.html (Accessed 5 June 2013).

Fullan, M. (2008). The six secrets of change. Jossey-Bass, San Francisco, CA, United States.

Guzzini, S. (2006) Applying Bourdieu's framework of power analysis to IR: opportunities and limits. Proceedings of the 47th Annual convention of the International Studies Association. $\quad$ Chicago, IL. http://pendientedemigracion.ucm.es/info/sdrelint/ficheros_materiales/materiales051.pdf (Accessed 5 May 2013)

Jenkins, A. and Healey, M. (2010) 'Undergraduate research and international initiatives to link teaching and research'. Council on Undergraduate Research, Vol. 30 No. 3, pp. 36-42.

Kordaki, M. (2010). The role of context free collaboration design patterns in learning design within LAMS: lessons learned from an empirical study. Proceedings of the 2010 European LAMS and Learning Design Conference, Sydney, NSW, Australia.

Millennial Branding (2012). Millennial branding student employment gap study. http://millennialbranding.com/2012/05/millenial-branding-student-employment-gap-study/ (Accessed 27 March 2013).

Oblinger, D. (2006) Learning Spaces. Educause, Washington, DC, United States. 
Rogers, C. (1969). Freedom to learn. Merill, Columbus, OH, United States.

Schmidt, S. (2010) 'Radical constructivism: A tool, not a super theory!' Constructivist Foundations, Vol. 6 No. 1, pp. 6-11.

Siemens, G. (2006). Knowing knowledge. http://www.elearnspace.org/KnowingKnowledge_LowRes.pdf . (Accessed: 27 March 2013).

Shechtman, N., deBarger, A., Dornsife, C., Rosier, S., and Yarnall, L. (2013) Promoting Grit, Tenacity, and Perseverance: Critical Factors for Success in the 21st Century. Draft Report prepared by the Centre for Technology in Learning, U.S. Department of Education Office of Educational Technology. http://www.ed.gov/edblogs/technology/files/2013/02/OET-DraftGrit-Report-2-17-13.pdf (Accessed 27 March 2013).

Su, Y. (2012) The development of 'learning to be' in higher education. In: C. Nygaard, J. Branch, and C. Holtham. Learning in Higher Education: Contemporary Standpoints, (pp. 167-181). Libri, Faringdon, England.

Soroka, V. and Safaeli, S. (2006) 'Invisible participants: How cultural capital relates to lurking behaviour. Proceedings of the $15^{\text {th }}$ international conference on World Wide Web, ACM, Edinburgh, Scotland. 